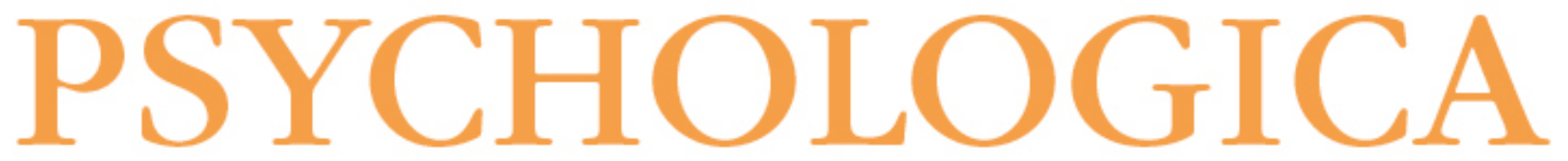

Funções na família multigeracional: contributo para a caracterização funcional do sistema familiar multigeracional

Autor(es): $\quad$ Vicente, Henrique Testa; Sousa, Liliana

Publicado por: Imprensa da Universidade de Coimbra

URL

persistente: URI:http://hdl.handle.net/10316.2/5531

DOI: DOI:http://dx.doi.org/10.14195/1647-8606_53_8

Accessed : $\quad$ 26-Apr-2023 16:02:48

A navegação consulta e descarregamento dos títulos inseridos nas Bibliotecas Digitais UC Digitalis, UC Pombalina e UC Impactum, pressupõem a aceitação plena e sem reservas dos Termos e Condições de Uso destas Bibliotecas Digitais, disponíveis em https://digitalis.uc.pt/pt-pt/termos.

Conforme exposto nos referidos Termos e Condições de Uso, o descarregamento de títulos de acesso restrito requer uma licença válida de autorização devendo o utilizador aceder ao(s) documento(s) a partir de um endereço de IP da instituição detentora da supramencionada licença.

Ao utilizador é apenas permitido o descarregamento para uso pessoal, pelo que o emprego do(s) título(s) descarregado(s) para outro fim, designadamente comercial, carece de autorização do respetivo autor ou editor da obra.

Na medida em que todas as obras da UC Digitalis se encontram protegidas pelo Código do Direito de Autor e Direitos Conexos e demais legislação aplicável, toda a cópia, parcial ou total, deste documento, nos casos em que é legalmente admitida, deverá conter ou fazer-se acompanhar por este aviso. 
NÚMERO 53

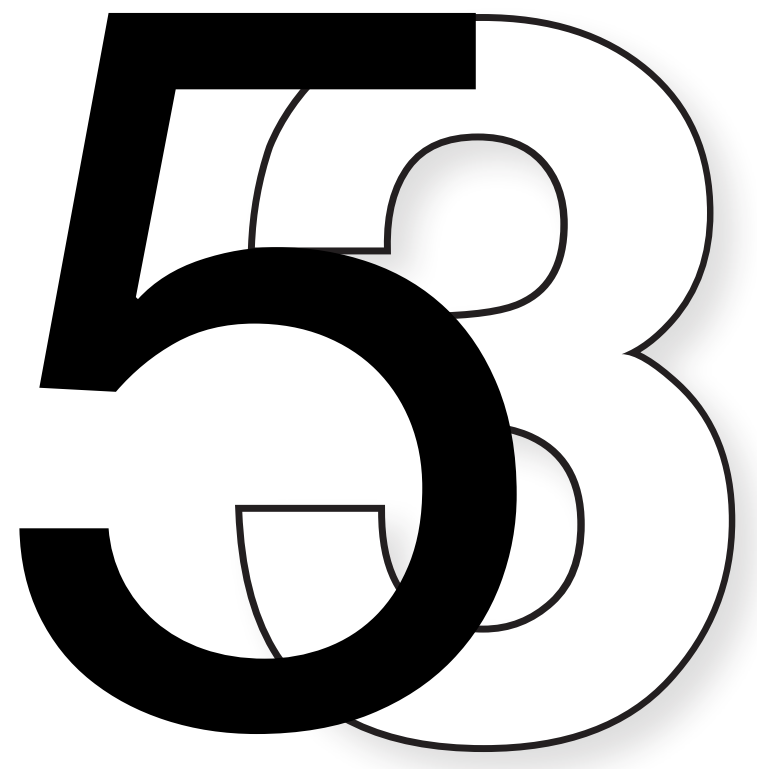

IMPRENSA DA UNIVERSIDADE DE COIMBRA

FACULDADE DE PSICOLOGIA E DE CIÊNCIAS DA EDUCAÇÃO DA UNIVERSIDADE DE COIMBRA 


\title{
Funções na família multigeracional: Contributo para a caracterização funcional do sistema familiar multigeracional'
}

\author{
Henrique Testa Vicente ${ }^{2}$ e Liliana Sousa ${ }^{3}$
}

\begin{abstract}
Esta pesquisa procura contribuir para a compreensão do sistema familiar multigeracional, centrando-se na análise das funções desempenhadas no seu seio e das características de quem as desempenha. Para tal, definiu-se um conjunto de funções a partir das características idiossincráticas da família multigeracional e aplicou-se uma entrevista de genograma a elementos das gerações intermédias de 25 famílias com elementos vivos de quatro gerações. Os papéis definidos em consonância com as funções identificadas são: "guardião das memórias familiares", "elo de ligação familiar" e "pronto-socorro familiar". Os dados apontam para um contributo mais equitativo das diferentes gerações para a dinâmica familiar multigeracional, ou seja, o funcionamento deste sistema parece depender da participação das suas várias gerações. Para além disso, os dados fornecem pistas para a intervenção familiar e facultam um contributo teórico para o tópico das famílias envelhecidas.
\end{abstract}

PALAVRAS-CHAVE: Família Multigeracional; Funções Familiares; Memórias Familiares; Ligações Familiares; Apoio Familiar.

\section{Introdução}

O estudo da família multigeracional assume relevância num quadro de mudanças históricas, sociais e demográficas que tornam o entrecruzar de gerações a mais peculiar característica da família contemporânea (Sousa, Figueiredo, \& Cerqueira, 2004). Como refere Prieur (1996/1999: IX): "tudo o que diz respeito à família se torna progressivamente mais universal e tudo funciona na coexistência e sucessão de gerações". Apesar do padrão de distanciamento geográfico dos núcleos fami-

\footnotetext{
1 Trabalho financiado pela Fundação para a Ciência e a Tecnologia do Ministério da Ciência, Tecnologia e Ensino Superior através de Bolsa de Investigação no âmbito do POCI 2010 - Formação Avançada para a Ciência - Medida IV.3 (referência SFRH / BD / 23545 /2005).

2 Professor Auxiliar - Instituto Superior Miguel Torga, Coimbra - henrique.t.vicente@ismt.pt

3 Professora Auxiliar com Agregação - Secção Autónoma de Ciências da Saúde, Universidade de Aveiro - lilianax@cs.ua.pt
} 
liares e individuos ser cada vez mais comum, o estudo da família multigeracional permanece importante, pois as famílias nucleares "continuam a ser subsistemas emocionais que reagem a relações do passado, presente e futuro antecipado dentro do sistema familiar trigeracional" (Carter \& McGoldrick, 2005: 3). Por isso, Minuchin e Fishman (1981) afirmam que a família extensa detém uma influência decisiva nas funções familiares nucleares.

Neste artigo, o termo "família multigeracional" designa famílias com representantes vivos de quatro gerações, apesar do conceito ser aplicável a famílias com três gerações. Trata-se de um conjunto de pessoas ligadas por laços de sangue ou de afinidade, vivendo ou não em coabitação, com diferentes distâncias geográficas e emocionais. Em geral, compreende diversos conglomerados habitacionais independentes, com um funcionamento relativamente autónomo, habitualmente apelidados "agregados familiares". Engloba elementos distribuídos por todo o espectro etário, implicando a coexistência e convivência de pessoas num mesmo sistema social com vivências sociais, históricas e culturais distintas.

Vicente e Sousa (2007) procuraram caracterizar a tópica estrutural das famílias multigeracionais, que se revelou divergente da família nuclear, identificando cinco subsistemas: a) indivíduo (unidade básica de todos os sistemas sociais), b) núcleo familiar (indivíduos em coabitação que partilham ou não laços familiares), c) composição familiar (associação, aliança ou coligação de dois ou mais núcleos familiares), d) geração (associação horizontal de indivíduos que partilham a mesma posição geracional), e) linhagem (associação vertical de indivíduos de diferentes gerações, pautada pela consanguinidade e partilha do património genético, envolvendo pessoas que partilham laços de ascendência ou descendência). A interacção destes subsistemas com duas variáveis (proximidade/distância geográfica e emocional) conduziu a uma tipologia estrutural com três categorias: a) família unificada (elevada proximidade geográfica e relacional), b) dispersa (elevada proximidade relacional e baixa proximidade geográfica), e c) fragmentada (baixa proximidade relacional). Numa amostra de famílias multigeracionais portuguesas, verificou-se que prevalecia o subtipo disperso.

No contexto das relações entre gerações, numerosos estudos se têm debruçado sobre pares relacionais muito específicos, por exemplo, avós e netos: estilos de ser avô (Neugarten \& Weinstein, 1968); funções educativas dos avós (Kivnick, 1982); papéis desempenhados pelos avós (Kornhaber \& Woodward, 1981); papel dos avós junto dos netos (Gonzaga \& Cruz, 2000). Estes estudos são efectivamente de carácter multigeracional, mas possuem um limitado poder compreensivo da dinâmica do sistema familiar multigeracional que contém, influencia e é influenciado por essas relações diádicas. 
Sendo a organização estrutural da família multigeracional diferente da família nuclear (Vicente \& Sousa, 2007), torna-se importante estudar a organização funcional desse sistema, cuja tradução, ao nível da vivência individual no contexto familiar, se revela no exercício de determinados papéis familiares. A família multigeracional possui características que a distinguem dos restantes sistemas sociais e essas idiossincrasias têm como corolário teórico a existência de necessidades particulares e tarefas relevantes para a sua "sobrevivência" enquanto sistema social de direito próprio. Estudar essas funções, através da identificação e caracterização dos elementos que as desempenham, afigura-se importante para promover o desenvolvimento dos seus membros, facilitar a resposta da família multigeracional a solicitações externas e internas e permitir a sua distinção dos restantes sistemas sociais.

\section{Funções e ciclo vital da família nuclear}

Minuchin (1982) concebe as tarefas da família em duas vertentes: a) a interna, referente à protecção psicossocial dos seus membros; e b) a externa, relativa à acomodação e à transmissão da cultura. A duplicidade funcional da família pode ser vista num sentido temporal: centrada no aqui e agora, nos problemas quotidianos dos seus membros; e espraiando-se no tempo, pelas questões desenvolvimentais que abarcam passado, presente e futuro (Sampaio \& Gameiro, 1985). As funções familiares são alvo de forte influência social e cultural, pelo que existem diferenças culturais e, com a evolução da sociedade, são expectáveis modificações.

As funções, papéis e tarefas na família nuclear foram amplamente estudados no âmbito do ciclo vital da família. O esquema de Carter e McGoldrick (2005), pela ênfase que coloca na perspectiva sistémica multigeracional de Bowen (1978/1984; Miller, Anderson \& Keala, 2004), ultrapassa a referência à família nuclear e alerta para os aspectos trigeracionais e para as "pontes genealógicas" entre gerações mais velhas e mais novas. Este esquema é um marco da aplicação do "ciclo vital da família" ao estudo das relações intergeracionais e da família multigeracional, pois reconhece a importância da família nuclear e da família extensa. Contudo, o enfoque desenvolvimental do "ciclo vital da família expandido", de Carter e McGoldrick (2005), centra-se na família nuclear, facultando, por acréscimo, uma espécie de "fotografia instantânea" da família multigeracional.

Todos os estádios de desenvolvimento familiar desse modelo implicam tarefas com base na interacção de dois subsistemas da família multigeracional: a geração e a linhagem. Por exemplo: no estádio "jovem adulto solteiro", o indivíduo/ 
família procura a diferenciação do self em relação à família de origem, ou seja, relativamente ao núcleo familiar de onde procede e à geração que o antecede; nas fases de "junção de famílias através do casamento" e de "famílias com filhos pequenos" emergem aspectos do subsistema linhagem, com as tarefas de realinhamento das relações com a família extensa para acomodar o cônjuge e, em seguida, incluir os papéis de "pais" e de "avós"; nas "famílias no fim vida”, a transição emocional centra-se na aceitação da mudança dos papéis geracionais e no apoio ao papel mais central das gerações intermédias, ao mesmo tempo que se lida com a perda de relações intrageracionais (cônjuge, irmãos e primos). Os tópicos intergeracionais e intrageracionais são transversais à vida da família, mas têm sido os estudos sobre a última fase do desenvolvimento familiar a debruçarem-se sobre o funcionamento da família multigeracional.

A importância da perspectiva transgeracional nos modelos de desenvolvimento familiar é reconhecida porque: existe continuidade nas famílias ao longo das gerações (por proximidade ou afastamento), ou seja, a identidade não se perde, renova-se (Sousa, 1998); essa continuidade é assegurada (Benoit, Malarewicz, Beaujean, Colas, \& Kannas, 1988) pelos fenómenos conscientes da educação e tradição familiar e pelos processos menos conscientes de delegação (Stierlin, 1978), lealdades invisiveis (Boszormenyi-Nagy \& Spark, 1984) e mitos (Ferreira, 1981). Estas vivências permitem manter a aliança entre a antiga e a nova família, ao mesmo tempo que se opera a adaptação a uma nova época.

\section{3. "Novas" funções na família multigeracional}

A revisão da literatura sobre relações intergeracionais permitiu destacar três tópicos com relevo para caracterizar as funções na família multigeracional: 1) a importância dos legados e heranças; 2) a complexidade das redes sociais familiares; 3 ) o papel central do apoio familiar, inserido no quadro mais vasto do apoio ou suporte social. Por seu turno, o sistema familiar multigeracional apresenta determinadas características idiossincráticas, a saber: a) percurso histórico longo e complexo que agrega a história dos indivíduos, núcleos e composições familiares, linhagens e gerações que o compõem; b) número elevado de subsistemas, pois são normalmente famílias com numerosos indivíduos, que se distribuem por diversos núcleos e múltiplas gerações e linhagens; c) coexistência de indivíduos e famílias nucleares em praticamente todas as fases do desenvolvimento individual e familiar, cada qual com tarefas e desafios particulares. Estas especificidades conduziram os autores a hipotetizar a existência de três funções essenciais neste sistema, as quais estão intimamente associadas aos temas abordados nos estudos sobre a 
intergeracionalidade: guarda das memórias familiares; ligação entre subsistemas; e apoio aos vários subsistemas.

A relevância destas funções, e das pessoas que as exercem e que assim passam a assumir um papel diferenciado e reconhecido socialmente, toca alguns referenciais teóricos que passamos a descrever.

\subsection{Guarda das memórias familiares}

O tema dos legados e das heranças emerge em termos da identidade familiar e individual, em estudos de sociologia da família (e.g. Goody, Thirsk, \& Thompson, 1976), psicologia da família (e.g. Patrão \& Sousa, 2008) e psicologia dinâmica (e.g. Prieur, 1999). Este tópico envolve relações entre subsistemas da família multigeracional, neste caso entre subsistemas geracionais. Apesar de se repercutirem no funcionamento da família nuclear, estas dinâmicas ocorrem sobretudo num nível de complexidade sistémica distinto: o sistema familiar multigeracional. Fine e Norris (1989) identificam a "transmissão intergeracional" de atitudes, orientações e/ou comportamentos como uma das áreas de investigação mais profícuas no domínio das relações intergeracionais, argumentando que não são fenómenos unidireccionais (das gerações mais idosas para as mais novas), mas bidireccionais. Por exemplo, a aprendizagem com as gerações mais novas parece deter um papel importante no envelhecimento bem sucedido das gerações mais idosas (Vaillant, 2002). Segundo Corigliano (1996/1999), a transmissão dos saberes, valores e códigos entre as gerações constitui o eixo vertical da memória familiar, ao passo que a ligação entre a microcultura familiar e o ecossistema sociocultural traduz-se no seu complementar eixo horizontal. Como o sistema familiar multigeracional possui uma longa e complexa história e como a memória é imprescindivel para o desenvolvimento e interacção humanas (Fonseca, 1997), os autores questionaram o seu papel no sistema familiar multigeracional. A inclusão da memória no plano sistémico não é novidade. Le Moigne (1978) refere-a num dos nove níveis da sua tipologia sistémica: a "memória" ocupa o sexto nível, depois da "decisão" e antecedendo a "coordenação ou pilotagem", permitindo que um sistema atinja o mundo da comunicação, que constitui um prolongamento do domínio da informação. Assim, neste estudo, hipotetizamos a existência de uma função de preservação das memórias familiares. Ao(s) actor(es) familiar(es) que desempenha(m) esta função atribuiu-se a designação de "guardião das memórias familiares".

\subsection{Ligação entre subsistemas}

A importância das ligações entre subsistemas na família multigeracional emerge nos estudos sobre redes sociais (Sluzki, 1996/2002), que salientam a impor- 
tância do contacto intergeracional e intrageracional. Relações entre bisavós e bisnetos, avós e netos, pais e filhos; relações cortadas, distantes ou fusionais; ligações entre agregados familiares desavindos, unidos ou coligados, ou entre elementos da mesma geração ou da mesma linhagem, constituem exemplos da miríade relacional das redes sociais familiares que envolvem a interacção de numerosos subsistemas familiares. Na família nuclear "tradicional”, composta por quatro elementos (o casal e dois filhos), podem ser identificados, pelo menos, oito subsistemas (quatro individuais, um parental, um conjugal, um filial e um fraternal), num total de 28 ligações possiveis entre eles. Um exercício matemático similar aplicado à família multigeracional seria bastante mais complexo. $\mathrm{O}$ número de ligações num sistema familiar multigeracional revelar-se-ia bastante superior, pois este é constituído por uma rede intrincada de relacionamentos entre subsistemas de proporção assinalável, embora variável com o número de elementos no sistema.

Os estudos sobre redes sociais enfatizam a existência de elementos que condensam um maior número de ligações e cuja anulação pode tornar a rede ineficaz e conduzir ao desmembramento. Granovetter $(1973,1983)$ apelidou estes elementos de "pontes sociais" ("social bridges"). Buchanan (2002), no seu seguimento, refere que os elos mais fracos numa rede podem ser de maior importância do que os elos fortes, pois actuam como laços cruciais que mantêm a rede unida e que, se eliminados, podem causar o colapso da rede. Estas ideias encontram reflexo nas relações familiares multigeracionais: os laços "fortes" seriam aqueles entre elementos dum núcleo ou agregado familiar (por exemplo, entre pais e filhos ou entre marido e mulher); enquanto os laços "fracos" ocorreriam entre gerações mais distantes (por exemplo, a geração mais nova e a mais idosa numa família de quatro gerações), entre linhagens distintas (por exemplo, entre compadres e comadres), ou entre núcleos ou agregados familiares dispersos geograficamente. Neste contexto, os autores hipotetizam a presença, na família multigeracional, de um ou mais elementos a exercer a função de ligação privilegiada entre subsistemas: o "elo de ligação familiar".

\subsection{Apoio aos vários subsistemas}

Numa família multigeracional existem indivíduos em praticamente todas as fases do desenvolvimento individual e familiar, apresentando necessidades variadas: a) individuais, decorrentes da posição no ciclo vital individual; b) familiares, associadas à vivência de cada núcleo familiar. A literatura sobre o suporte e apoio familiar tem-se centrado no papel de cuidador familiar de longa duração ao idoso (Figueiredo, 2007) e nas trocas de apoio entre pais e filhos ao longo da vida (Rossi \& Rossi, 1990). Outros estudos reportam-se a relações diádicas, mas abrangem 
um espectro geracional mais alargado, por exemplo, quando os avós assumem os cuidados dos netos (Goodman \& Silverstein, 2001; Hader, 1965; Poehlmann, 2003). Estes estudos apenas revelam uma das facetas do apoio familiar, aquele que é continuado e estendido no tempo, relegando para segundo plano o apoio prestado pontualmente ou numa emergência. Ao abordar os fluxos de stress na família (Carter \& McGoldrick, 2005), verifica-se que acidentes, imprevistos e vicissitudes fazem parte da vida individual e familiar e requerem características particulares por parte de quem ajuda. Como a família multigeracional é habitualmente composta por numerosos agregados familiares, cada qual confrontado com tarefas inerentes à fase do ciclo vital em que se encontra, é de esperar que as necessidades sejam múltiplas e diversas e que, quando um problema é resolvido, logo surja outro noutra parte do sistema. Nesta linha, consideramos a possibilidade de haver um ou mais elementos que funcionem como interventores na crise, facultando primeiras ajudas, aconselhamento e/ou encaminhamentos: o "pronto-socorro familiar".

\section{Objectivos}

Este estudo explora e a profunda três funções na família multigeracional ("guarda das memórias familiares" "ligação familiar" e "apoio familiar"), principalmente através da caracterização das pessoas que os assumem no seio familiar. A relevância desta pesquisa está na continuação do contributo para o desenvolvimento de um modelo de compreensão da família multigeracional (Vicente \& Sousa, 2007). Este estudo é ainda relevante num plano interventivo, pois os resultados têm implicações na planificação da intervenção e na compreensão do funcionamento familiar.

\section{Metodologia}

Esta pesquisa integra-se num projecto de investigação mais abrangente no âmbito das famílias multigeracionais. Assim, torna-se necessário contextualizar a recoIha dos dados sobre as "novas" funções na família multigeracional. No desenho metodológico alargado existem dois momentos de recolha de dados: $1^{\circ}$ ) junto de um elemento das gerações intermédias ( $G_{2}$ ou $G_{3}$, sendo que $G_{1}$ corresponde à geração mais idosa e $\mathrm{G}_{4}$ à geração mais nova) procede-se à construção do genograma familiar (através de uma entrevista construída segundo as indicações constantes em McGoldrick e Gerson, 1987); $2^{\circ}$ ) junto de um representante de cada geração na família é aplicado o IARSP-R (Instrumento de Avaliação das Redes Sociais Pessoais - forma Revista) (Alarcão \& Sousa, 2007). 
As questões sobre as funções na família multigeracional, das quais provêm os dados deste artigo, são colocadas no final da entrevista de genograma, representando a visão singular e idiossincrática de um sujeito acerca da sua família e da problemática colocada pelo entrevistador. Depois de elaborado o genograma, o entrevistador coloca a seguinte questão aberta centrada nas funções familiares acima elencadas:

\begin{abstract}
"Considerando todos os membros da sua familia representados neste genograma, existe algum que assuma, consciente ou inconscientemente, algum dos seguintes papéis: guardião das memórias familiares; elo de ligação entre elementos da familia; pronto-socorro familiar em momentos de crise, emergência ou necessidade pontual?"
\end{abstract}

Quando o entrevistado dá uma resposta negativa, expressa alguma dúvida ou pede esclarecimentos, o entrevistador acrescenta informação sobre cada um dos papéis: a) o "guardião das memórias familiares" é "o repositório das memórias ou da identidade familiar, alguém que conhece as histórias, os mitos e os segredos familiares ou que guarda fotografias ou outros objectos relevantes para contar a história da família"; b) o "elo de ligação familiar" é o membro da família "que funciona como ponte de ligação entre vários núcleos ou agregados da família alargada, aquele que mantém bons relacionamentos com a maioria dos familiares e que facilita a circulação de informação"; c) o "pronto-socorro familiar" é "alguém na familia a quem os restantes recorrem numa emergência ou momento de aflição, a quem é reconhecida competência e disponibilidade para facultar uma primeira ajuda". Após a resposta e identificação do(s) elemento(s), o entrevistador solicita que o respondente caracterize cada personagem no panorama familiar e que enumere os aspectos pessoais ou atributos que motivaram a escolha.

Este momento foi eleito para colocar as questões relativas às funções na família multigeracional porque: a) após a realização do genograma o entrevistado já efectuou um esforço de reflexão sobre a sua família alargada, estando mais sensibilizado para os problemas deste sistema; b) o material gráfico (genograma) permite uma visão global do sistema familiar alargado; c) o elevado número de familiares identificados através da elaboração de um genograma de quatro gerações aumenta as opções de resposta.

As questões foram colocadas a um elemento da família, e sabe-se que indivíduos diferentes pertencentes à mesma família podem apresentar percepções discrepantes em relação ao seu meio e dinâmica familiares (Olson et al., 1989). O recurso a múltiplos informadores numa família poderia contribuir para o enriquecimento desta análise. 


\subsection{Amostra}

A amostra compreende 25 famílias multigeracionais (com elementos vivos de quatro gerações), tendo sido recolhida pelo processo de amostragem em bola-de-neve. 0 processo decorreu do seguinte modo: após a realização da entrevista de genograma, era perguntado ao participante se tinha contacto com outras famílias com as mesmas características; em caso de resposta afirmativa, era muitas vezes o entrevistado a apresentar a nova família ao investigador, que repetia o processo. Desta forma, as famílias distribuem-se por um conjunto limitado de concelhos da região centro de Portugal, aos quais o investigador tinha acesso. Seria difícil realizar uma amostragem aleatória da população portuguesa, ou mesmo de uma localização geográfica mais limitada, pois não existem registos, por exemplo nas Juntas de Freguesia, sobre quais as famílias portuguesas com elementos vivos de quatro gerações.

Os inquiridos pertencem às gerações intermédias das famílias multigeracionais em estudo: 10 são de $\mathrm{G}_{2}$ e 15 de $\mathrm{G}_{3}$. A maioria dos entrevistados é do sexo feminino, sendo que apenas dois (8\%) pertencem ao sexo masculino. A média etária dos inquiridos é de 43,52 anos. Quanto à situação na profissão, $84 \%$ enquadram-se na categoria "empregado", $8 \%$ "doméstico", $4 \%$ "estudante" e $4 \%$ "reformado". Relativamente ao estado civil, verificou-se uma predominância da categoria "casado" (64\%), seguindo-se "divorciado" (20\%), "solteiro" (8\%), "separado" (4\%) e "união de facto” (4\%).

\subsection{Análise dos dados}

A análise contemplou dois conjuntos de dados: 1) as características sócio-demográficas dos elementos identificados como desempenhando algum dos papéis referenciados (sexo, idade, estado civil, situação na profissão, posição geracional), ou seja, a informação recolhida durante a elaboração do genograma; 2) as descrições e caracterizações efectuadas pelos entrevistados acerca dos elementos que desempenham os papéis (como é que caracteriza este elemento?) e as justificações para as respostas (porque seleccionou este elemento e não outro?). As informações veiculadas foram anotadas pelo entrevistador (primeiro autor) em folhas de registo, para que o entrevistado pudesse confrontar visualmente o genograma e as suas respostas. A duração das entrevistas foi variável, desde os 30 minutos até às 2 horas.

Os dados sócio-demográficos foram analisados através da estatística descritiva. As descrições sobre os papéis e quem os desempenha foram submetidas a análise de conteúdo, de acordo com um processo que compreendeu duas fases: 1) construção de categorias e subcategorias para a definição dos papéis, tendo em conta a literatura e os dados das entrevistas; 2) classificação das respostas dos inquiridos nas (sub)categorias. 
O primeiro momento consistiu na criação de um sistema de classificação através de um processo de refinamento progressivo, envolvendo dois juízes independentes (os autores). Cada juiz leu as entrevistas e desenvolveu uma lista de categorias e subcategorias que considerou pertinente. Posteriormente, reuniram-se e discutiram ambas as propostas até um consenso ser estabelecido (Tabela 1.).

O segundo momento consistiu na classificação das entrevistas por cada um dos juízes de forma independente, à luz da lista categorial. Numa reunião subsequente, debateram e analisaram as discordâncias entre as duas categorizações produzidas. Os níveis de concordância entre investigadores foram calculados através da seguinte fórmula: fiabilidade = número de concordâncias/número total de concordâncias + discordâncias. Os resultados foram os seguintes: a) concordância global - 69,52\%; b) "guardião das memórias familiares" - 68,1\%; "elo de ligação familiar"-73,79\%; "pronto-socorro familiar" $-66,67 \%$. Todos os valores representam níveis de fiabilidade razoáveis para esta fase do processo (Huberman \& Miles, 1991). As respostas em que houve discordância foram analisadas posteriormente pelos juízes, que chegaram a uma concordância de: 97,41\% para o "guardião das memórias familiares"; 98,06\% para o "elo de ligação familiar"; e 99,07\% para o "pronto-socorro familiar". As frequências constantes na tabela 3 revelam as concordâncias no final deste processo, pelo que as classificações em que os juízes não chegaram a uma concordância não foram consideradas.

Tabela 1. Categorias e subcategorias: definições e exemplos

\begin{tabular}{|c|c|c|}
\hline (Sub)Categorias & Definição & Exemplos \\
\hline \multicolumn{3}{|c|}{ 1. Aspectos funcionais: caracterização do desempenho de papel } \\
\hline Transmissão & $\begin{array}{l}\text { Acto de legar, transmissão intergeracional } \\
\text { e/ou intrageracional de elementos nar- } \\
\text { rativos/históricos, valores morais e/ou } \\
\text { objectos materiais. }\end{array}$ & $\begin{array}{l}\text { "Tem interesse e preo- } \\
\text { cupação em transmitir a } \\
\text { história familiar" }\end{array}$ \\
\hline $\begin{array}{l}\text { 1.2. Memória e } \\
\text { conservação }\end{array}$ & $\begin{array}{l}\text { Preservação e conservação de elementos } \\
\text { narrativos/históricos, valores morais e/ou } \\
\text { objectos materiais; pode ser compreen- } \\
\text { dida com referência ao acto de arquivar. }\end{array}$ & $\begin{array}{l}\text { "Fez a árvore genealógica } \\
\text { da família e colecciona } \\
\text { fotografias" }\end{array}$ \\
\hline $\begin{array}{l}\text { 1.3. Continui- } \\
\text { dade familiar }\end{array}$ & $\begin{array}{l}\text { Aspectos funcionais herdados, que } \\
\text { representam e transmitem uma ideia de } \\
\text { continuidade e integridade das relações } \\
\text { familiares alargadas. }\end{array}$ & $\begin{array}{l}\text { "Os membros da família } \\
\text { que estão a herdar esta } \\
\text { função não têm as mesmas } \\
\text { características que ela" }\end{array}$ \\
\hline $\begin{array}{l}\text { 1.4. Conexão e } \\
\text { manutenção }\end{array}$ & $\begin{array}{l}\text { Manutenção e conexão de subsistemas na } \\
\text { família alargada; promoção de encon- } \\
\text { tros e abertura de vias de comunicação; } \\
\text { promoção da união familiar alargada; } \\
\text { promoção da solidariedade intergeracional } \\
\text { e intrageracional na dimensão associativa, } \\
\text { frequência do contacto social e actividades } \\
\text { partilhadas (Silverstein \& Bengtson, 1997). }\end{array}$ & $\begin{array}{l}\text { "Ligam a família dos dois } \\
\text { lados, do meu e do meu } \\
\text { marido" }\end{array}$ \\
\hline
\end{tabular}



1.5. Apoio e
suporte
Apoio prestado na resolução de problemas (saúde, financeiros, quotidianos, gestão de conflitos e relações); promoção da solidariedade intergeracional e intrageracional na dimensão funcional, de trocas de assistência e apoio financeiro e instrumental (Silverstein \& Bengtson, 1997).

1.6. Intervenção na crise

Primeiro apoio quando algum familiar é confrontado com um problema; a primeira pessoa a quem se pede ajuda.
"Eles estão disponíveis para ajudar nas tarefas do quotidiano"

\section{\begin{tabular}{ll}
\hline 2. Características sócio-demográficas associadas ao desem \\
\hline 2.1.Idade & $\begin{array}{l}\text { A idade é relevante para o exercício de } \\
\text { um papel; inclui a posição na fratria. }\end{array}$ \\
$\begin{array}{ll}\text { 2.2. Sexo } & \text { O sexo é relevante no exercício do papel. } \\
\begin{array}{l}\text { 2.3. Localização } \\
\text { geográfica }\end{array} & \begin{array}{l}\text { A zona de residência é relevante no } \\
\text { desempenho do papel. }\end{array} \\
\begin{array}{l}\text { 2.4. Situação na } \\
\text { profissão }\end{array} & \begin{array}{l}\text { A situação na profissão (empregado, } \\
\text { desempregado, doméstico, reformado, } \\
\text { estudante) é relevante para o papel. }\end{array}\end{array}$
\end{tabular}}

2.5. Actividade Relevo da actividade profissional (p. ex. profissional

2.6. Recursos económicos

2.7. Recursos materiais

2.8. Disponibilidade de tempo ista) edos conhecimentos associados. ista) e dos conhecimentos associados. Saliência dos recursos económicos/financeiros para o exercício do papel. habitação, etc.) são relevantes para o exercício do papel.

Ter tempo disponível (por exemplo, devido a desemprego ou reforma); difer-
"Quando algo acontece é o primeiro a chegar"

\section{família"}

"A minha residência é central em relação à dos meus familiares"

"Como é doméstica, está mais a par do que se passa!"

"Por ser médico"

Os recursos materiais (p. ex. computador, ente da disponibilidade pessoal (inserida no ponto 3. características pessoais).
"É a pessoa com mais meios, tem uma vida estável"

"Porque vive numa casa grande"

"Por ter maior disponibilidade de horários!"

\section{Características pessoais: traços de personalidade, carácter ou aspectos inerentes ao}

funcionamento do indivíduo que assume a função

\begin{tabular}{|c|c|c|}
\hline 3.1. Conciliador & $\begin{array}{l}\text { Procura minimizar ou resolver conflitos; } \\
\text { pôr de acordo partes desavindas; pacifi- } \\
\text { car e harmonizar; promover a união. }\end{array}$ & $\begin{array}{l}\text { "Assumiu o papel de gestor } \\
\text { de conflitos" }\end{array}$ \\
\hline 3.2. Sociofilia & $\begin{array}{l}\text { Tendência para procurar contactos com o } \\
\text { meio social, num gosto das implicações } \\
\text { sociais; desinibição. }\end{array}$ & $\begin{array}{l}\text { "Nós gostamos de conviver, } \\
\text { ter gente à volta" }\end{array}$ \\
\hline
\end{tabular}

3.3. Saudosismo Apego ou nostalgia pelo passado; saudade pela ausência ou desaparecimento de pessoas, coisas, estados ou acções; não implica tristeza ou outra emoção negativa.

3.4. Curiosidade Desejo e/ou interesse por saber ou conhecer.

3.5. Simpatia

Participa nos estados afectivos dos outros; compaixão; trato agradável; boa disposição e humor.

"São pessoas sensiveis e saudosistas, mais ligadas às tradições e ao passado"

"Eu tenho curiosidade em saber de onde eram os meus avós"

"É genuinamente simpática, é uma pessoa agradável” 
3.6. Ponderação Prudente; manifesta capacidade de reflectir; avalia maduramente; tem em conta várias perspectivas; expõe os seus pontos de vista com argumentos convincentes.

3.7. Culpabilidade

\subsection{Controlo}

3.9. Iniciativa

3.10. Valores religiosos 3.11. Disponibilidade

3.12. Competências comunicativas

3.13. Credibilidade

3.14. Competência de resolução de problemas festa tendências auto-punitivas; manifesta sentimentos de responsabilidade por actos ou omissões repreensíveis.

\section{Procura controlar, orientar, fiscalizar o} próprio (auto-controlo) e/ou os outros tendência para a organização. prática uma acção ou ideia; assume a prestação de apoio sem lhe ser solicitada. religioso que influencia a conduta. para ajudar; solidariedade.

Comunica facilmente com outras pessoas; transmite informação de forma clara; esclarece mal-entendidos. à pessoa visada da característica "sabedoria".

Capacidade de analisar um problema, pensar em possiveis soluções e colocálas em prática; eficiência.
Experiencia sentimentos de culpa; mani(hetero-controlo); pode revelar-se numa

“É uma pessoa com sensibilidade e bom senso"

"Talvez se sinta culpada de ter sido a única a construir uma família"

"Tentou sempre dominar a família, ter tudo sobre controlo, ter a família em seu redor"

"Aceitam logo de imediato ajudar, não hesitam"

Conjunto de valores com base num credo

Pessoa que se pode chamar para ajudar a resolver qualquer problema; não significa desocupação, mas uma predisposição

Digno de crédito; inspira confiança; boa reputação; pode revelar-se na atribuição
"Ele é uma pessoa católica e, como tal, ajuda os outros" "Dispõe-se a ajudar as pessoas e por isso recorrem a ele"

"Nós contactamo-nos mais eficazmente"

"É uma pessoa respeitada na família e fora dela"

"Ele é desenrascado"

\section{Resultados}

A existência destas funções nas famílias foi patente na facilidade com que a maior parte dos entrevistados identificava elementos da família que assumiam os papéis. Vejamos a caracterização das pessoas identificadas como desempenhando cada um dos papéis (Tabela 2.). 


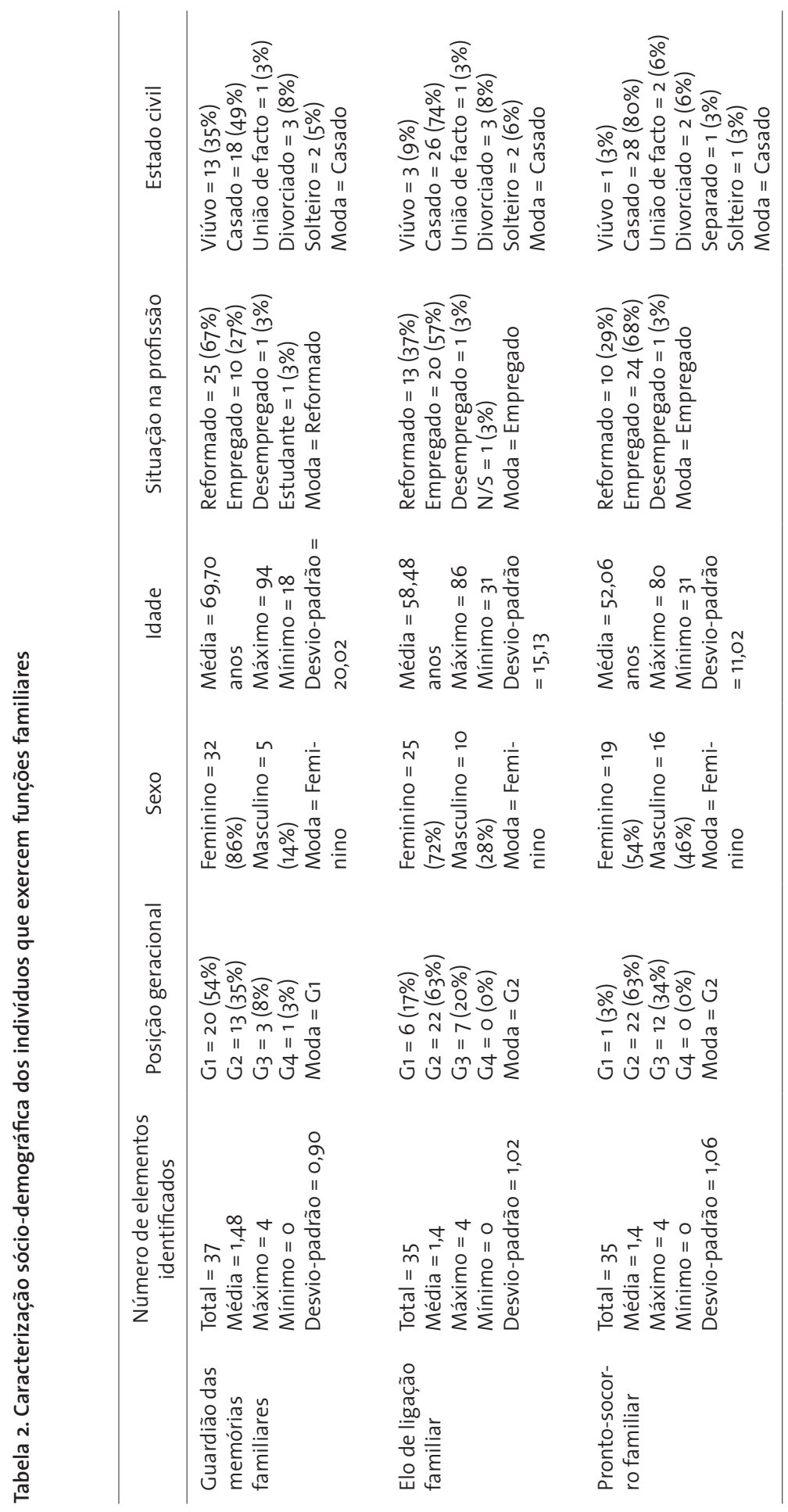


Em geral foi identificado um ou mais elementos na família a cumprirem cada uma das funções (Tabela 2.). A identificação de múltiplos elementos para o mesmo papel aponta para duas possibilidades explicativas cuja conjunção pode melhor traduzir a experiência familiar: a) a ocorrência de fragmentação ou dispersão da família multigeracional (Vicente \& Sousa, 2007), que pode conduzir à duplicação de papéis pela desconexão dos subsistemas; $b$ ) o exercício de qualquer uma destas funções faz parte da experiência e personalidade de cada indivíduo, embora uns o façam com maior proeminência, frequência e alcance, razão pela qual são destacados e reconhecidos. Esta possibilidade é reiterada quando alguns entrevistados não indicam nenhum elemento como exercendo a função, pois afirmam que é praticada por todos os membros da família (importa salientar que na ausência de uma resposta específica por parte do entrevistado, quando não refere um ou mais indivíduos assinalando que a função é desempenhada por "todos", não é contabilizado qualquer elemento da família).

Os três papéis predefinidos apresentam características que os aproximam. Quanto à posição geracional verifica-se que: o "guardião das memórias familiares" pertence principalmente a G1 ou a G2; o "elo de ligação familiar" e o "pronto-socorro familiar" tendem a pertencer a G2 ou a G3. Apenas foi identificado um elemento de $\mathrm{G}_{4}$ a exercer uma função, a de "guardião de memórias familiares". Estas funções multigeracionais recaem principalmente em $\mathrm{G}_{2}$, seguindo-se $\mathrm{G}_{1}$ e $\mathrm{G}_{3}$ consoante a função se repercute mais no plano simbólico e narrativo ou no campo mais pragmático do apoio familiar. Em termos de sexo, todas as funções são maioritariamente exercidas por mulheres, embora os homens apresentem valores percentuais próximos no caso do "pronto-socorro familiar". Ao nível da idade, o "guardião das memórias familiares" é tendencialmente mais velho, seguindo-se o "elo de ligação familiar" e, por último, o "pronto-socorro familiar". A situação na profissão acaba por reflectir a idade de quem exerce as funções: o "guardião das memórias familiares" tende a estar reformado; o "elo de ligação familiar" e o "pronto-socorro familiar" tendem a estar empregados. O estado civil segue uma linha paralela. Embora em todos os papéis se verifique um predomínio de indivíduos casados, a frequência de viúvos é superior entre os "guardiães das memórias familiares".

Vejamos agora a caracterização dos papéis em termos funcionais e os atributos conferidos à personagem que os desempenha (Tabela 3.). 
Tabela 3. Características dos papéis familiares

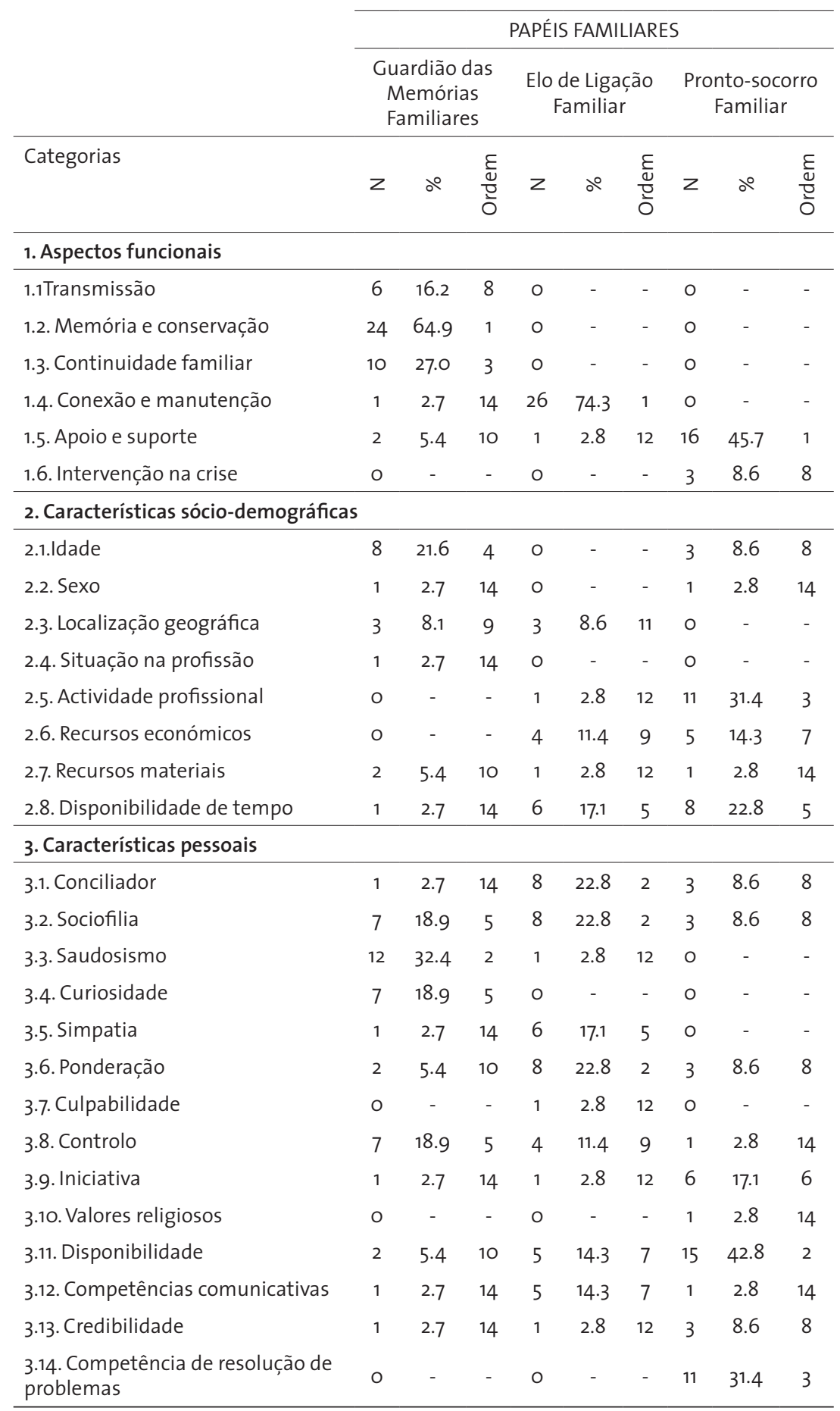




\section{1. "Guardião das memórias familiares"}

O "guardião das memórias familiares" tem como função essencial a "memória e conservação" e, em alguns casos, também a "transmissão". Trata-se de uma função que em $27 \%$ dos casos foi ou será herdada, o que suporta a sua importância na manutenção da continuidade familiar. A idade é referenciada como relevante para o exercício deste papel. Em termos de características pessoais, destaca-se o "saudosismo", seguido da "sociofilia", "curiosidade" e "controlo". Ficou patente que os recursos pessoais necessários para exercer esta função são mais difíceis de quantificar do que, por exemplo, os rendimentos económicos, a disponibilidade de tempo ou as competências de resolução de problemas, que figuram abundantemente na literatura sobre relações intergeracionais.

\section{2. "Elo de ligação familiar"}

O "elo de ligação familiar" exerce quase exclusivamente uma função de "conexão e manutenção" entre os subsistemas da família multigeracional. A disponibilidade de tempo, os recursos económicos e financeiros e a localização da sua residência são elementos sócio-demográficos que parecem contribuir para o exercício da função. As características pessoais são: "conciliador", "sociofilia" e "ponderação", ou seja, pessoas que procuram e desejam contactos sociais e que procuram fazê-lo com tacto e sensibilidade, muitas vezes no sentido de solucionar conflitos. Outras características incluem: "simpatia", "disponibilidade", "competências comunicativas" e "controlo".

\section{3. "Pronto-socorro familiar"}

O "pronto-socorro familiar" revela-se como prestador de "apoio familiar" e, com menos frequência, como elemento de "intervenção em crise". Isto apesar da nomenclatura atribuída a esta personagem, nas questões colocadas, poder induzir os entrevistados a responder nesse sentido. Este dado é relevante do ponto de vista metodológico, conferindo validade às caracterizações funcionais dos restantes papéis, pois nestes também a nomenclatura utilizada nas questões poderia influenciar as respostas.

A actividade profissional aparece como o elemento sócio-demográfico mais relevante para o exercício desta função. Os entrevistados identificaram familiares com profissões específicas (p. ex. médicos, enfermeiros, advogados, contabilistas), acrescentando que os conhecimentos profissionais e a rede desenvolvida nestes meios são fundamentais para o apoio ao sistema familiar. Outro elemento sócio-demográfico relevante parece ser a disponibilidade de tempo: o "pronto-socorro familiar", apesar de ser uma personagem profissionalmente activa, tem tempo 
para dedicar à família. Além disso, emerge a disponibilidade de recursos financeiros ou económicos, essenciais para facultar apoios mais instrumentais. No plano das características pessoais, salienta-se: a “disponibilidade pessoal” (é alguém a quem se pode recorrer, com predisposição para ajudar); as "competências de resolução de problemas"; e, com percentagens distantes das anteriores, encontram-se as subcategorias "conciliador", "sociofilia", "ponderação" e "credibilidade”.

que aponta no sentido da reciprocidade intersistémica entre indivíduo, família nuclear e multigeracional; b) as diferenças de género na assunção de papéis dentro da família multigeracional, reafirmando o papel das mulheres na família mas reintegrando igualmente o sexo masculino no capital social familiar; c) as diferenças etárias entre os familiares que exercem as funções definidas, que traçam um ponto de contacto entre sistema familiar multigeracional, desenvolvimento individual e familiar.

Ficou patente que o "pronto-socorro familiar" e o "elo de ligação" tendem a estar casados e a pertencer às gerações intermédias. Ao estudarem os efeitos dos cuidados e apoios multigeracionais, Loomis e Booth (1995) não encontraram dados que confirmassem a hipótese de uma geração de adultos de meia-idade sobrecarregada. Uma das explicações avançadas pelos autores sugere a existência de um efeito selectivo na família, em que as pessoas com maiores capacidades de assumir as responsabilidades pelos apoios as tomam para si próprias. Nesse estudo, os dados revelaram que as pessoas com casamentos mais "fortes" tendiam a assumir responsabilidades multigeracionais. De facto, as pessoas casadas de meia-idade encontram-se no estádio "generatividade vs. estagnação" (Erikson, 1950/1976), ou seja, estão empenhadas no cuidado das gerações subsequentes (e antecedentes) como forma de avançar no desenvolvimento individual. Além disso, encontram-se no epicentro relacional de vários subsistemas geracionais e de linhagem. Assim, o facto do "pronto-socorro familiar" e do "elo de ligação familiar" partilharem estas características parece traduzir sobretudo a reciprocidade intersistémica entre indivíduo, subsistema conjugal, família nuclear e família multigeracional, ou seja, a complementaridade e acoplagem das tarefas inerentes a diferentes subsistemas. Os sujeitos identificados encontram-se efectivamente na convergência e ligação de duas linhagens distintas decorrentes do casamento, estão situados numa posição de charneira entre subsistemas geracionais, que muitas vezes necessitam 
de cuidados, e atravessam uma fase do desenvolvimento individual cujas tarefas se coadunam precisamente com a "conexão" e o "cuidado" do outro.

As funções de ligação entre subsistemas e guarda das memórias familiares são maioritariamente exercidas por mulheres, ao passo que o exercício do apoio 174 familiar aos subsistemas revela uma distribuição menos desproporcional entre os sexos. Elementos de ambos os sexos parecem assim estar envolvidos e implicados no funcionamento do sistema familiar multigeracional, mas com abordagens e prioridades distintas. Os estudos sobre relações sociais e maturidade filial na meia-idade sugerem uma atitude mais pragmática dos homens em relação à prestação de apoio familiar, enquanto as mulheres apresentam maior tendência sociofílica. Assim, as mulheres têm mais contacto com os seus pais e amigos, enquanto os homens tendem a centrar as relações no cônjuge. Perrig-Chiello e Sturzenneger (2001) consideram que essa diferença pode ser atribuível ao papel tradicional do sexo feminino: assumir a responsabilidade pelos assuntos sociais dentro e fora da família.

Importa salientar a associação do exercício da função de guarda das memórias familiares aos elementos mais idosos. Tal é consistente com o processo de construção da integridade familiar (King \& Wynne, 2004), típica das famílias envelhecidas, que envolve a criação de legados a partir da partilha de histórias ou rituais entre as gerações, e com a proposta de Vaillant (2002) de inclusão do estádio "guardião do significado" ("keeper of the meaning") no seu esquema desenvolvimental, embora este último se reporte a uma esfera social mais vasta, não limitada à família. Trata-se de uma função desempenhada essencialmente por mulheres, frequentemente viúvas. Estes dados poderiam indiciar um papel associado ao género, mas uma explicação mais simples pode ser avançada a partir do diferencial entre a esperança média de vida de homens e mulheres. Ou seja, os homens não sobrevivem o suficiente para exercerem com maior frequência este papel. O exercício desta função no contexto familiar alargado permite compreender as relações entre gerações de forma mais equitativa e equilibrada. Quando as pessoas idosas "contam histórias do passado", estão a encontrar significados para as suas vidas, mas também a providenciar às gerações mais novas uma forma de reinterpretarem o presente e as suas histórias individuais em função das suas experiências, interesses e contexto cultural, ou seja, trata-se de um empreendimento dialógico (Tschuggnall \& Welzer, 2002). Ambas as partes parecem beneficiar da transmissão: tanto os dadores, pela extensão do self nas gerações seguintes (Price, Arnould, \& Curasi, 2000); como os recipientes, que adquirem elementos que os ajudam a desenvolver a própria identidade (Spira \& Wall, 2007). Contudo, também o todo, a família multigeracional, retira ganhos desta relação, pois vê preservada a sua história.

A memória revela-se um elemento fundamental no desenvolvimento e interacção humanas pois, sem memória, não haveria passado nem futuro, apenas presente. 
Segundo Fonseca (1997: 361), "foram sobretudo os trabalhos de Bartlett (1967) que nos revelaram a função reconstrutiva da memória e a sua participação imprescindivel, quer no domínio de actividades psicológicas altamente abstractas como a «imaginação", quer na execução de atitudes pragmáticas como o "hábito". Estes elementos acoplados a outro nível sistémico - a família - traduzem-se da seguinte forma: a memória familiar será indispensável para a família perspectivar ou imaginar formas diferentes de funcionamento pois, sem o reconhecimento de um padrão (particularmente os disfuncionais), não é possível alterá-lo; as memórias familiares também assumem uma função quotidiana, regulando e moldando as actividades familiares.

As funções de preservação, conservação e transmissão da memória poderão ser uma das pedras de toque do edifício sistémico familiar multigeracional, conferindo à geração mais idosa um lugar de destaque, muitas vezes ignorado nos estudos da família. Esta posição encontra fundamento na maior importância atribuída à dimensão processual (sobre a dimensão material) pelos proponentes dos modelos cibernéticos que providencia uma nova imagem "científica" do self incorpóreo (Davis, 1999: 90), uma imagem que reconceptualiza como padrões de informação aquilo que usualmente definimos como identidade. Como referia Wiener (1954), a individualidade de um organismo parece residir sobretudo numa continuidade de processos e na memória do seu desenvolvimento passado. Nesta perspectiva, a continuidade do sistema familiar multigeracional parece residir na geração habitualmente percepcionada como dependente desse sistema e cujo peso actual na sociedade é resultado de mudanças recentes, em particular do aumento da longevidade.

Todas as funções parecem encontrar eco teórico nos desafios enfrentados pelos sistemas (Durand, 1979/1992: 26): a) "estabelecer uma boa coordenação dos comportamentos" (manutenção de laços e comunicação através do "elo de ligação familiar"); b) "encontrar respostas adequadas às perturbações provenientes do meio" (e às oriundas do interior, onde se inclui a função do "pronto socorro familiar"); c) "aprender novos comportamentos" (sendo a memória indispensável à aprendizagem, o "guardião das memórias familiares" é fundamental para a evolução do sistema familiar alargado). De assinalar que estas três funções se fazem sentir essencialmente no vivido familiar alargado, embora possam ter o seu correlato no sistema familiar nuclear (p. ex. pode existir alguém que assuma o papel de preservar e compilar a história da família nuclear).

\subsection{Implicações para a intervenção familiar}

As implicações de um modelo teórico desenvolvido para a compreensão do sistema familiar multigeracional são múltiplas. Neste caso, centramo-nos nas implicações da sua análise estrutural e funcional no domínio da intervenção familiar. Por exem- 
plo: o "guardião das memórias familiares", quando identificado e chamado à sala de terapia familiar, poderá contribuir para a identificação de padrões familiares e para o desvendar das suas origens, elementos de manutenção e de transformação; o "elo de ligação familiar" e o "pronto-socorro familiar", nas intervenções em rede, poderão potenciar os resultados terapêuticos, pois podem activar ligações entre subsistemas e mobilizar recursos para a resolução dos problemas.

É possível avançar um exemplo mais concreto, no campo do aconselhamento genético onde é amplamente reconhecida a importância da família na vida do cliente. Daly e colaboradores (1999) exploraram as relações familiares no aconseIhamento de risco oncológico, utilizando o genograma. Nesse estudo, o genograma incidia na identificação de membros da família com doenças do foro oncológico e nos padrões relacionais e comunicacionais. Eram avaliadas as relações do cliente com tios e tias, avôs e avós, frequentemente negligenciadas por constrangimentos de tempo ou falta de contacto com a família extensa. Esta limitação poderia ser colmatada através da identificação e recurso ao "elo de ligação familiar", pois estas pessoas procuram contactos sociais, abrindo vias de comunicação entre subsistemas, promovendo a união familiar inter e intrageracional.

A identificação do "guardião das memórias familiares" e a sua colaboração no processo poderá aumentar a precisão da informação familiar ao dispor da equipa multidisciplinar de aconselhamento genético, e auxiliar no planeamento de estratégias de intervenção centradas na família. No estudo supracitado, verificou-se que, apesar de mais de $75 \%$ dos participantes terem concordado em partilhar a informação do aconselhamento genético com a família, uma percentagem significativa reportou ter dificuldades emocionais em fazê-lo. O genograma familiar alargado e a consequente ênfase colocada na dinâmica familiar multigeracional, assim como a identificação e inclusão de indivíduos que cumprem funções relevantes no seio deste sistema, de guarda das memórias, ligação entre subsistemas e apoio familiar na crise, poderá ser um passo nesse sentido.

\section{Conclusões}

Torna-se relevante elaborar alguns comentários acerca das implicações epistemológicas deste estudo sobre funções na família multigeracional, assim como do precedente centrado na sua análise estrutural (Vicente \& Sousa, 2007). Ambos os estudos procuram facultar os mecanismos para a construção de uma prototeoria do sistema familiar multigeracional fundada no paradigma ou metamodelo sistémico. Segundo Baltes e Willis (1977), a avaliação de teorias ou modelos passa por três aspectos: lógica interna; relação entre afirmações teóricas e evidências 
empíricas; relação entre as três funções de uma teoria (geração, disseminação e utilização do conhecimento).

Relativamente à lógica interna, apenas a realização de estudos subsequentes permitirá avaliar a consistência e testabilidade dos conceitos. Em caso afirmativo, o alcance e espectro de aplicabilidade deste modelo é vasto e ultrapassa as possibilidades deste artigo. Desde a psicologia da família, passando pela terapia familiar, em particular os modelos estruturais e transgeracionais, até à psicologia do desenvolvimento familiar e individual, as possibilidades são numerosas.

Quanto à relação entre afirmações teóricas e evidências empíricas, a literatura sobre relações intergeracionais tem facultado suporte à proposta estrutural avançada. Além disso, a facilidade de resposta dos entrevistados às questões sobre funções na família multigeracional vai de encontro às contextualizações teóricas que guiaram a construção do questionário.

A relação entre as três funções de uma teoria merece uma reflexão mais aprofundada. Consideramos que os dados quantitativos, de caracterização dos elementos que exercem funções nas famílias multigeracionais, cumprem um papel secundário, sendo que o principal contributo da análise estrutural e funcional do sistema familiar multigeracional se revela no plano teórico e conceptual. Enquanto ferramenta de trabalho para o profissional, saber em que posição geracional se encontra, por exemplo, o "guardião das memórias familiares", é um conhecimento de valor limitado, pois a experiência familiar é alvo de influências sociais e históricas. Em virtude da rapidez das mudanças sociais, será natural que os dados acerca dos elementos que assumem papéis na família multigeracional se alterem num futuro mais ou menos próximo. Um tópico imediato recai no impacto da disseminação generalizada das "novas" tecnologias na dinâmica familiar alargada. Por exemplo, os computadores e as máquinas fotográficas e câmaras digitais, com capacidades de memória cada vez maiores, poderão alterar a forma como são preservadas as memórias familiares. Estas questões enfatizam que a abrangência e aplicabilidade da identificação de funções familiares multigeracionais específicas deste nível sistémico, num quadro de rápidas alterações sociais e familiares, resistirá melhor aos efeitos do tempo e às alterações supracitadas e terá maiores repercussões na geração, disseminação e utilização do conhecimento (Baltes \& Willis, 1977), do que os dados quantitativos revelados pelo estudo.

Contudo, os dados quantitativos apresentam alguma utilidade. No caso deste estudo, a constatação do exercício de funções familiares multigeracionais fundamentais por parte das gerações idosas vem contrariar a visão contemporânea prevalecente dos idosos como meros consumidores de recursos e facultar-lhes uma posição de relevo no sistema familiar alargado. 
A prototeoria apresentada é, então, que a família multigeracional consiste num sistema de direito próprio, situado entre a comunidade e a família nuclear, num esquema hierárquico sistémico de complexidade variável, que possui características distintivas, e que implica o exercício de determinadas funções por parte dos seus membros com vista à sua sobrevivência. Este sistema não existiria se não contribuísse para o bem-estar dos elementos que o compõem, dos mais novos aos mais velhos, pelo que, aparentemente, o exercício destas funções na família multigeracional contribui igualmente para o desenvolvimento dos indivíduos.

\section{Referências bibliográficas}

Alarcão, M. \& Sousa, L. (2007). Rede social pessoal: Do conceito à avaliação. Psychologica, $44,353-376$.

Baltes, B. P. \& Willis, S. L. (1977). Towards psychological theories of aging and development. In J. E. Birren \& K. W. Schaie (Eds.). Handbook of the psychology of aging. New York: Van Nostrand Reinhold.

Benoit, J., Malarewicz, J., Beaujean, J., Colas, Y., \& Kannas, S. (Eds.) (1988). Dictionnaire clinique des thérapies familiales systémiques. Paris: ESF.

Boszormenyi-Nagy, I. \& Spark, G. M. (1984). Invisible loyalties. Levittown, PA: Brunner/Mazel. (Obra original publicada em 1973).

Bowen, M. (1984). La différenciation du soi, les triangles et les systèmes émotifs familiaux. Paris: ESF. (Obra original publicada em 1978).

Buchanan, M. (2002). Small world: Uncovering nature's hidden networks. London: Weidenfeld \& Nicolson.

Carter, B. \& McGoldrick, M. (Eds.). (2005). The expanded family life cycle: Individual, family, and social perspectives. New York: Allyn \& Bacon.

Corigliano, A. (1999). A dimensão transgeracional entre o mito e o segredo. In B. Prieur (Coord.) As heranças familiares (pp. 75-86). Lisboa: Climepsi Editores. (Obra original publicada em 1996).

Daly, M., Farmer, J., Harrop-Stein, C., Montgomery, S., Itzen, M., Costalas, J. W., Rogatko, A., Miller, S., Balshem, A., \& Gillespie, D. (1999). Exploring family relationships in cancer risk counseling using the genogram. Cancer Epidemiology, Biomarkers \& Prevention, 8, 393-398.

Davis, E. (1999). Techgnosis: Myth, magic + mysticism in the age of information. London: Serpent's Tail.

Durand, D. (1992). A sistémica. Lisboa: Dinalivro. (Obra original publicada em 1979).

Erikson, E. H. (1976). Infância e Sociedade (2 ed.). (G. Amado, Trans.). Rio de Janeiro: Zahar Editores. (Obra original publicada em 1950).

Ferreira, A. (1981). Les mythes familiaux. In Y. Winkin (Ed.) La nouvelle communication. Paris: Éditions du Seuil.

Figueiredo, D. (2007). Cuidados familiares ao idoso dependente. Lisboa: Climepsi Editores.

Fine, M. \& Norris, J. E. (1989). Intergenerational relations and family therapy research: What we can learn from other disciplines. Family Process, 28 (3), 301-315. 
Fonseca, A. F. (1997). Psiquiatria e psicopatologia (I Volume). Lisboa: Fundação Calouste Gulbenkian.

Gonzaga, A. \& Cruz, O. (2000). A percepção dos avós acerca das suas relações inter-geracionais. Infância e Educação: investigação e práticas, 1, 97-118.

Goodman, C. C. \& Silverstein, M. (2001). Grandmothers who parent their grandchildren. Journal of Family Issues, 22 (5), 557-578.

Goody, J., Thirsk, J., \& Thompson, E. P. (Eds.). (1976). Family and inheritance: Rural society in western Europe 1200-1800. Cambridge: Cambridge University Press.

Granovetter, M. (1973). The strenght of weak ties. American Journal of Sociology, 78 (6), 1360-1380.

Granovetter, M. (1983). The strenght of weak ties: A network theory revised. Sociological Theory, 1, 201-233.

Hader, M. (1965). The importance of grandparents in family life. Family Process, 4, 228-240.

Huberman, A. M. \& Miles, M. B. (1991). Analyse des données qualitatives: Recueil de nouvelles méthodes. Bruxelles: De Boeck-Wesmael.

King, D. A. \& Wynne, L. C. (2004). The emergence of "family integrity" in later life. Family Process, 43 (1), 7-21.

Kivnick, H. O. (1982). Grandparenthood: An overview of meaning and mental health. The Gerontologist, 22, 59-66.

Kornhaber, A. \& Woodward, K. (1981). Grandparents/grandchildren, the vital connection. New York: Anchor Press/Doubleday.

Le Moigne, J. L. (1978). La théorie du système general. Paris: PUF.

Loomis, L. S. \& Booth, A. (1995). Multigenerational caregiving and well-being: The myth of the beleaguered sandwich generation. Journal of Family Issues, 16 (2), 131-148.

McGoldrick, M. \& Gerson, R. (1987). Genogramas en la evaluación familiar. Barcelona: Gedisa Editorial.

Meisser, W. W. (1964). Thinking about the family-psychiatric aspects. Family Process, 3, 1-40.

Miller, R. B., Anderson, S., \& Keala, D. K. (2004). Is Bowen theory valid? A review of basic research. Journal of Marital and Family Therapy, 30 (4), 453-466.

Minuchin, S. (1982). Familias, funcionamento e tratamento. Porto Alegre: Artes Médicas.

Minuchin, S. \& Fishman, H. (1981). Family therapy techniques. Cambridge, Massachusetts: Harvard University Press.

Neugarten, B. \& Weinstein, K. (1968). The changing American grandparent. In B. Neugarten (Ed.) Middle age and aging. London: University of Chicago Press.

Olson, D. H., McCubbin, H. I., Barnes, H. L., Larsen, A. S., Muxen, M. J., \& Wilson, M. A. (1989). Families: What makes them work. London: Sage.

Patrão, M. \& Sousa, L. (2008). Transmissão da herança material: Uma tarefa normativa das famílias envelhecidas. Psychologica (submetido).

Perrig-Chiello, P. \& Sturzenneger, M. (2001). Social relations and filial maturity in middleaged adults: contextual conditions and psychological determinants. Zeitschrift für Gerontologie und Geriatrie, 34, 21-27.

PoehImann, J. (2003). An attachment perspective on grandparents raising their very young grandchildren: Implications for intervention and research. Infant Mental Health Journal, 24 (2), 149-173.

Price, L. L., Arnould, E. J., \& Curasi, C. F. (2000). Older consumers' disposition of special possessions. Journal of Consumer Research, 27, 179-201. 
Prieur, P. (Coord.) (1999). As heranças familiares. Lisboa: Climepsi Editores. (Obra original publicada em 1996).

Rossi, A. \& Rossi, P. (1990). Of human bonding: Parent-child relations across the life course. New York: Aldine de Gruyter.

Sampaio, D. \& Gameiro, J. (1985). Terapia familiar. Porto: Edições Afrontamento.

Sluzki, C. E. (2002). La red social: Frontera de la practica sistemica (3 ed.). Barcelona: Gedisa Editorial. (Obra original publicada em 1996).

Silverstein, M. \& Bengtson, V. L. (1997). Intergenerational solidarity and the structure of adult child-parent relationships in American families. American Journal of Sociology, 103, 429-460.

Sousa, L. (1998). Crianças (con)fundidas entre a escola e a familia: Uma perspectiva sistémica para alunos com necessidades educativas especiais. Porto: Porto Editora.

Sousa, L., Figueiredo, D., \& Cerqueira, M. (2004). Envelhecer em familia. Porto: Âmbar.

Spark, G. M. \& Brody, E. M. (1970). The aged are family members. Family Process, 9, 195-210.

Spira, M. \& Wall, J. (2006). Issues in multigenerational families: Adolescents' perceptions of grandparents declining health. Child and Adolescent Social Work Journal, 23 (4), 390-406.

Stierlin, H. (1978). Delegation und familie. Franckfurt: Suhrkamp.

Tschuggnall, K. \& Welzer, H. (2002). Rewriting memories: Family recollections of the national socialist past in Germany. Culture \& Psychology, 8 (1), 130-145.

Vaillant, G. E. (2002). Aging well: Surprising guideposts to a happier life from the landmark Harvard Study of Adult Development. Boston: Little, Brown and Company.

Vicente, H. T. \& Sousa, L. (2007). Família multigeracional: Estruturas típicas. Contributo para a avaliação do sistema familiar. Psychologica, 46, 143-166.

Wiener, N. (1954). The human use of human beings. New York: Doubleday Anchor Books.

\section{Functions in the multigenerational family: Towards a functional charac- terization of the multigenerational family system}

This research aims to contribute to the comprehension and understanding of multigenerational family systems, mainly focusing on the analysis of specific functions performed within this system and on the personal characteristics of the individuals who assume them. To achieve this goal the authors defined a limited set of functions drawn from idiosyncratic characteristics of the multigenerational family and applied a genogram interview to elements of the intermediate generations of 25 families with living elements of four distinct generations. Specific roles were defined in accordance with the functions identified based on the literature: "keeper of family memories", "connecting link in the family" and "family first aider". The results point to a fairer and more equitable contribution of different generations to the multigenerational family dynamic. That is, it seems that the adequate functioning and survival of this system depends on the commitment and participation of its several generations. Beyond that, the data supplies guidelines for family intervention and offers a theoretical contribution to the topic of aging families.

KEY-WORDS: Multigenerational Family; Family Functions; Family Memories; Family Links; Family Support. 
Les fonctions dans la famille multi-générationnelle: pour une caractérisation fonctionnelle du système familier multi-générationnelle

Cette recherche prétend contribuer à la compréhension du système familial multi-générationnel, dirigeant son attention sur l'analyse de ses fonctions et des caractères spécifiques de ceux qui les accomplissent. À cette fin, un ensemble de fonctions a été défini, à partir des caractères idiosyncratiques de la famille multi-générationnelle, et un entretien à génogramme a été appliqué à certains éléments des générations intermédiaires de 25 familles, composées d'éléments vivants de quatre générations. Les rôles définis qui s'accordent aux fonctions identifiées sont: le " gardien des mémoires familiales ", le " maillon familial » et le «secouriste familial ». Les données obtenues indiquent une participation plus équitable de la part de chaque génération pour la dynamique familiale multi-générationnelle, autrement dit, le fonctionnement de ce système semble ressortir de la participation de ses diverses générations. En plus, les données fournissent des pistes pour l'intervention familiale et accordent un contribut théorique pour le thème des familles vieillissantes.

MOTS-CLÉS: Famille Multi-générationnelle; Fonctions Familiales; Mémoires Familiales; Liaisons Familiales; Soutiens Familiaux 